\title{
IMPEACHMENT E O PRINCÍPIO DA LEGALIDADE COMO DIREITO HUMANO: CONTEÚDO, APLICABILIDADE E DEVER DE CONTROLE SOBRE O JUÍZO POLÍTICO
}

\author{
IMPEACHMENT AND THE LEGALITY PRINCIPLE AS A HUMAN \\ RIGHT: CONTENT, APPLICABILITY AND JUDICIAL REVIEW
}

\author{
Eduardo Pitrez de Aguiar CorrêA*
}

\begin{abstract}
RESUMO
O estudo de casos de impeachment na América Latina após a redemocratização revela que julgamentos políticos podem eventualmente representar burlas a este importante mecanismo de responsabilização. Situações nas quais o processo de impeachment é uma justificativa retórica do parlamento para depor o chefe do poder executivo, em contextos de crise macroeconômica, disputa entre poderes e baixa aprovação popular. A presença de um crime de responsabilidade não seria, em tais casos, o elemento determinante do resultado do processo. No julgamento da ADPF 378/ DF o STF declarou não lhe caber sindicar a imputação de crime de responsabilidade, restringindo sua atuação ao controle da forma do processo. $\mathrm{O}$ artigo, a partir de pesquisa bibliográfica e documental, sustenta o equívoco do entendimento. No direito internacional dos direitos humanos a compreensão sobre o conteúdo normativo do princípio da legalidade demanda a incorporação de duas perspectivas: (i) o princípio da legalidade aplica-se ao direito sancionatório como um todo; e (ii) a análise de uma eventual prática estatal arbitrária em juízos sancionatórios demanda observar o comportamento estatal anterior e o contexto no qual a decisão foi proferida. Ao declarar a imunidade da deliberação parlamentar, o órgão de cúpula do Poder Judiciário brasileiro, além de potencialmente encampar uma infringência ao art. 9 (princípio da legalidade) da $\mathrm{CADH}$, promove uma violação ao art. 25 (direito à proteção judicial) da Convenção pelo Brasil, sujeitando
\end{abstract}

\begin{abstract}
The study of cases of impeachment in Latin America after redemocratization reveals that political judgments may sometimes represent mockery of this important accountability mechanism. These are situations in which the process of impeachment is a rhetorical justification of the parliament to depose the head of the executive branch, in contexts of a macroeconomic crisis, power struggle and low popular approval. In such cases, the existence of a crime may not be the determining factor in the outcome of the proceedings. In the judgment of ADPF 378/ $D F$, the Brazilian Supreme Court (STF) declared that it would not review the charge of an impeachable conduct, thus, restricting its action to control the form of the process. This paper, which is based on a bibliographical and documentary research, maintains that the Court is wrong. In international human rights law, the understanding of the meaning of the principle of legality demands the acceptance of two premises: (i) the principle of legality applies to state sanctions as a whole; and (ii) the analysis of a possible arbitrary state practice in sanctioning demands that both the previous state behavior and the context in which the decision was rendered are observed. When the STF declares the immunity of the parliamentary decision, it takes the risk of accepting the violation of Article 9 (principle of legality) of the American Convention on Human Rights (ACHR) and promotes the violation of Article 25 (right to judicial protection) of the
\end{abstract}

* Professor Adjunto da Faculdade de Direito da Universidade Federal do Rio Grande (FADIR/ FURG), na graduação e no Mestrado em Direito e Justiça Social (PPGDJS/FURG). Doutor e Mestre pela Pontifícia Universidade Católica do Rio Grande do Sul (PUCRS). MBA pela Fundação Getúlio Vargas (FGV). Investigador Visitante na Universidade de Castilla-La Mancha (2014) e na Corte Interamericana de Direitos Humanos (2011).

E-mail: eduardo.pitrez.correa@furg.br. 
a República à responsabilidade internacional.

PALAVRAS-CHAVE: Sistema interamericano de direitos humanos. Impeachment Princípio da Legalidade.
Convention by Brazil, subjecting the Republic to international responsibility.

KEYWORDS: Inter-American Human Rights System. Impeachment. Principle of Legality.

SUMÁRIO: 1. Introdução 2. Novo modelo de deposição de governos na América Latina 3. Dever de controle e limites do juízo político 3.1 Por que o Tribunal Constitucional deve sindicar a imputação? 3.2 O paradigma interamericano de controle 4. Conteúdo do princípio da legalidade, como direito humano, no controle do juízo político 5. Direito Humano à legalidade e o caso brasileiro 6. Conclusões. Referências.

\section{INTRODUÇÃO}

Qual o lugar do direito não instrumentalizado pela disputa política, em um ambiente de polarização próprio de um processo de impedimento do chefe do poder executivo? O conteúdo do juízo político é insindicável, bastando que se respeite determinado procedimento? Não há, neste domínio, um controle formal e material da deliberação parlamentar? Clássico dentre os direitos humanos consagrados nos sistemas interamericano e universal, qual o aporte que o princípio da legalidade pode dar ao julgamento que se instaura, em órgão parlamentar, em face dos assim-chamados crimes de responsabilidade do Chefe do Poder Executivo?

O presente estudo pretende contribuir para as respostas a essas indagações, que poderiam ser reformuladas com a definição do seguinte problema: qual o parâmetro de controle do princípio da legalidade, como direito humano, para o julgamento por crime de responsabilidade de chefes do Poder Executivo em países inseridos no Sistema Interamericano de Direitos Humanos - SIDH?

Para responder a essa pergunta, o artigo explora o conteúdo normativo do princípio da legalidade, não o fazendo, contudo, a partir de compreensões de “direito interno", mas desde uma perspectiva do direito internacional dos direitos humanos, tendo em vista a necessária fertilização das compreensões nacionais por esta referência jurídico-humanitária.

$\mathrm{O}$ estudo parte de investigação empírica sobre os principais processos de deposição presidencial na América Latina a partir da década de 80 do século XX que, com base na análise de casos, apontou um conjunto de características que permite reunir esses processos de deposição presidencial como expressões de um padrão regional. Na mesma linha, aponta pedido de opinião consultiva da Comissão Interamericana de Direitos Humanos - CIDH que explicita preocupação com as mais recentes manifestações de juízo político no continente, articulando a preservação de direitos humanos e do regime democrático com processos de impeachment na região. 
A seguir, partindo da exposta realidade dessas experiências, sustenta o dever de controle material e formal do julgamento político, fins de salvaguardar não apenas os direitos da pessoa implicada, mas também a não instrumentalização do direito para fins de disputa política, com riscos à própria democracia materialmente concebida. Com essa preocupação, postula que o juízo político, a despeito de beneficiário de uma margem de apreciação, não goza de imunidade material, e está conformado por condicionantes indisponíveis que lhe devem ser impostas em caso de inobservância, por força da normatividade superior que é própria dos direitos humanos.

Por fim, critica a postura absenteísta do Tribunal Constitucional brasileiro, afirmando o dever de controle da imputação feita em juízo político, indicando a relevância e a aplicabilidade do controle do princípio da legalidade, na perspectiva do direito internacional dos direitos humanos, para o processo de impeachment ocorrido no Brasil.

\section{NOVO MODELO DE DEPOSIÇÃO DE GOVERNOS NA AMÉ- RICA LATINA}

A experiência histórica não permite desconhecer que na América Latina os modos de estruturação do poder político e suas correspondentes formas fático-jurídicas estiveram de maneira geral inseridos em experiências regionalizadas, por sua vez emolduradas por elementos de geografia política que desbordavam, no mais das vezes, do próprio continente americano. Os países latino-americanos possuem uma identidade histórica, política, social e econômica que permite, se não exige, a sua compreensão em conjunto. ${ }^{1}$ Sem negar as diferenças existentes entre esses países, os elementos de identificação regional conformam um espaço que se encontra reunido não somente pela experiência de colonização ibérica comum, mas também pelos subsequentes modos de estruturar e consolidar as relações de poder nas sociedades latino-americanas. Crer que, no curso dessa ainda recente experiência de democratização que marca o continente a partir dos anos 80 do século XX, os elementos de identificação regional não devam ser observados, é acreditar no fim da história.

De modo geral, uma compreensão de conjunto, devidamente localizada, para a teoria jurídica na América Latina não é novidade. Pelo contrário, dentre outros setores consideráveis da doutrina, autores da estatura de Zaffaroni ${ }^{2}$ postulam há muito um saber marcado pelo locus latino-americano, pelas experiências reais de poder que aqui se manifestaram e ainda se manifestam, o que em sua construção conduz a perspectiva de que, na América Latina, o realismo marginal seja a premissa metodológica necessária para a abordagem das manifestações de poder, em especial do poder de punir.

\footnotetext{
1 MENEZES, 2010.

2 ZAFFARONI, 1988.
} 
Não é necessário adotar o realismo marginal, todavia, para perceber a relevância de uma perspectiva contextualizada do tema do impeachment se se quer afastar as retóricas jurídico-políticas que se articulam no debate público e institucional em torno ao afastamento do chefe do executivo pelo parlamento. Em uma controvérsia que envolve tantos interesses, disputas e paixões, encontrar o espaço destinado ao direito não instrumentalizado pelo jogo das relações de poder recomenda, pelo menos, duas reservas metodológicas: contextualização do fenômeno e incorporação de conhecimento baseado em evidência. A contextualização busca referências fora do momento e do ambiente de disputa, especialmente válidas quando há reprodução do fenômeno sob investigação dentro de um mesmo período histórico e de uma mesma região. Por sua vez, a incorporação de conhecimento baseado em evidência acolhe perspectivas fundadas em dados de realidade que busquem descrever o fenômeno em suas diversas manifestações conhecidas, e não apenas justificá-lo ou contestá-lo, como sói ocorrer com o direito.

$\mathrm{Na}$ linha dessas premissas, pesquisa conduzida por Aníbal Pérez-Liñán, ${ }^{3}$ analisando a estruturação e o desenvolvimento dos principais processos de impeachment na América Latina a partir do período de redemocratização, é capaz de fornecer importantes elementos para encontrar-se o lugar do direito não instrumentalizado na abordagem do impedimento presidencial pelo parlamento. A investigação de Perez-Liñan identificou um novo modelo de desestabilização e deposição de governos na América Latina a partir do último decênio do século XX: o impeachment ou juicio político.

Segundo dados explorados pelo autor, nos quarenta anos que antecederam a década de 90 do século XX, somente um caso na região poderia ser virtualmente reportado como de impeachment, o do Panamá, em 1955. Mesmo que o processo de impeachment estivesse já previsto nas diversas constituições então existentes, o instrumento padrão pelo qual governos eram depostos na região era outro: o golpe militar. Entre 1950 e 2004, 42 golpes militares ocorreram na América Latina, especialmente por força do movimento conservador em resposta à revolução cubana (1959). Entre os anos 60 e 70 do século passado governos democráticos em toda a região viriam a ser sucessivamente depostos por golpes militares, então o mecanismo utilizado para resolver as disputas entre as elites civis-militares no contexto de um conjunto de interesses internos e internacionais.

Após décadas de submissão a regimes ditatoriais responsáveis por graves violações de direitos humanos, a América Latina passou por um processo de redemocratização que ganhou força na década de 80 do século passado. Uma série de constituições democráticas foi promulgada e, ao menos sob o ponto de vista formal, o continente é fundamentalmente democrático. Organizações

3 PÉREZ-LIÑÁN, 2007. 
internacionais de âmbito regional (OEA) e subregional (MERCOSUL) adotaram tratados (Carta Democrática Interamericana e Protocolo de Ushuaia II, respectivamente) que erigem a democracia representativa à condição de direito dos povos do continente.

A alteração do cenário internacional e a experiência das ditaduras no poder modificaram a capacidade e o interesse das elites civis-militares em manter o modelo anterior. Sem a viabilidade do recurso à intervenção militar, as elites civis foram forçadas a encontrar formas com possível justificativa constitucional para resolver suas disputas, desmilitarizando o modelo de deposição presidencial na região. ${ }^{4}$

Essa mudança de "estratégia política" conduziria a três principais consequências.

Primeiro, o novo modelo de resolução da disputa política tende a não ameaçar a forma de regime democrático, que nessa referência se mantém formalmente inalterado. Os sucessivos impeachments na região não impediram que, em geral, após a queda do governo deposto e a ascensão do governo substituto fossem realizadas novas eleições para o mandato subsequente.

Segundo, diferentemente da referência anterior, no novo modelo o legislador é quem pode "dissolver o presidente". No período militarizado, as casas legislativas eram frequentemente dissolvidas pelo executivo, mandatos parlamentares eram cassados e a oposição política parlamentar era perseguida. Já nas constituições presidencialistas que caracterizam a região após 1977, o presidente não está habilitado a dissolver o Congresso, e seus membros, empoderados por essas mesmas Constituições a remover o presidente, se acham em uma posição mais segura, invertendo a dinâmica de forças entre os poderes relativamente às possibilidades de interrupção de mandato. Como resultado, estatisticamente no método militar e no método parlamentar os presidentes na região mantêm chances equivalentes de deposição no período militarizado e no das constituições democráticas, com pequeno incremento das deposições no método parlamentar $(38,5 \% \times 40,6 \%)$.

Terceiro, a nova via tornou os legisladores mais suscetíveis a dois elementos catalíticos centrais do modelo contemporâneo de deposição: a mídia e as organizações da sociedade civil. Enquanto a primeira pode expor casos de corrupção e abuso necessários para iniciar um processo de impeachment, as últimas são as responsáveis por ativar a mobilização popular em torno aos eventos noticiados e desestabilizar o governo, permitindo e forçando a ação do legislativo. ${ }^{5}$

Segundo a investigação do pesquisador argentino, em todos os casos de impeachment na região um dado comum foi a existência de um escândalo, no

\footnotetext{
4 PÉREZ-LIÑAN, 2007.

5 PÉREZ-LIÑAN, 2007.
} 
contexto de uma crescente utilização do escândalo como arma política, viabilizada pela disseminação do alcance e o empoderamento da mídia corporativa. Todavia, o escândalo tornou-se um elemento necessário, mas não suficiente para ativar o modelo parlamentar de deposição parlamentar. Enquanto um presidente corrupto poderá estar imune a escândalos se o país vive um bom momento econômico, mesmo um político honesto é suscetivel à exposição escandalosa e fragilizadora em tempos de crise, tendo em vista a determinante correlação entre desempenho macroeconômico e (des)aprovação popular, dois elementos fundamentais para as iniciativas de deposição.

Inseridos nessa dinâmica, os atores relevantes para deflagrar o modelo contemporâneo de deposição não atuam de maneira isolada do contexto político, e, portanto, necessariamente motivados pela existência ou nível de corrupção do executivo. Ao oposto, de modo a permitir e forçar a atuação do legislativo quando há espaço para tanto, atuam justamente no quadro do contexto político e estimulados por uma audiência ávida por críticas, especialmente em momentos de crise macroeconômica. Com efeito, dentre as alterações visíveis com o novo modelo, está a mudança de percepção das elites relativamente aos movimentos da sociedade civil. Enquanto no modelo anterior os movimentos eram interpretados como manifestações ideológicas, e eram combatidos com posturas radicais, inclusive violentas, no modelo contemporâneo determinadas mobilizações da sociedade civil são lidas como expressões de isolamento do executivo e janelas de oportunidade para ativação da via parlamentar de deposição. Por isso, não é imprescindivel para a iniciativa e para o sucesso de um processo de impeachment a existência real de um crime que o justifique, mas sim um Congresso que, na presença de um contexto histórico adequado, seja mais ou menos inclinado a processar ou a proteger o chefe do poder executivo a partir de um escândalo, daí a centralidade das relações executivo - parlamento para a funcionalidade do método parlamentar. ${ }^{6}$

A propensão dos legisladores para atuar em um ou outro sentido não é, assim, necessariamente condicionada pela existência do crime impeditivo ou de sua prova. Segundo as evidências investigadas, o comportamento do legislador é consequência (i) da postura e da liderança do presidente em relação ao congresso; (ii) de motivações partidárias e (iii) do ambiente político do momento de crise.

Portanto, em substituição ao método militar de deposição presidencial próprio do período da Guerra Fria, há um novo padrão regional, agora desmilitarizado, de afastamento do chefe do poder executivo: a via parlamentar do impeachment. Esse novo padrão pode ser identificado pelo conjunto de fatores que se reproduzem nas jovens democracias latinoamericanas para a interrupção de mandatos presidenciais a partir dos anos 80 do século passado, sendo ativado

6 PÉREZ-LIÑAN, 2007. 
ou desativado, circunstancialmente, pelas não tão jovens estruturas de poder dos países da região, sempre a pretexto de cumprir as constituições.

A evidência dos fatos despertou a atenção de órgãos do SIDH. A CIDH, instância quase-judicial com atribuição para demandar perante a Corte Interamericana de Direitos Humanos - Corte IDH, pendendo sobre si a análise de três casos de impeachment na região (Paraguai, Honduras e Brasil), e tendo expressado anteriormente sua preocupação em relação ao eles, submeteu à Corte IDH pedido de opinião consultiva que correlacionava democracia e direitos humanos.

Dentre outras indagações, a Comissão questionou sobre "quais salvaguardas devem existir, tanto na regulação como na prática, para prevenir o uso de juízos políticos realizados pelo Poder Legislativo contra Presidentes/as democrática e constitucionalmente eleitos/as, como forma de golpe de Estado encoberto?" 7 Para a CIDH, as situações ocorridas nestes países alertavam sobre “possíveis casos de desnaturalização da figura do juízo político, e o consequente risco de que seja utilizado de maneira arbitrária de tal forma que encubra um golpe parlamentar." 8

Embora a Corte não tenha respondido à consulta, porque estava direcionada a casos concretos pendentes de deliberação pela CIDH - o que desvirtuaria a função consultiva da Corte $-^{9}$, o conteúdo da petição basta para denunciar a suspeita de juízos políticos fraudulentos, que desbordam dos limites de atuação do poder público nas modernas democracias constitucionais, potencialmente atingindo direitos convencionalmente assegurados.

\section{DEVER DE CONTROLE E LIMITES DO JUÍZO POLÍTICO}

O estudo de Pérez-Liñan e a abordagem pela CIDH dos juízos políticos na região colocam o modelo contemporâneo de deposição presidencial na América Latina como um procedimento que de modo geral orbita entre duas possibilidades: um equivalente funcional dos golpes de estado civis-militares ou um mecanismo de responsabilização, no sistema constitucional de freios e contrapesos, do chefe do executivo autor de uma conduta definida como impeditiva da continuidade do mandato.

Na primeira hipótese há uma instrumentalização da previsão constitucional de impedimento de mandato que se estabelece na disputa das relações de poder em determinada sociedade. Para isso, substitui-se o modelo de força armada (golpes civis-militares) por um modelo de "força retórica", isto é, baseado em razões, ainda que somente aparentes, de direito constitucional, invocadas para "dissolver o presidente" eleito em contextos de disputa política, crise macroeconômica e desaprovação popular. Nesse caso, há um "refinamento" do método

\footnotetext{
7 CIDH, 2017, p.16, grifamos.

8 CIDH, 2017, p.3, grifamos.

9 CORTE IDH, 2018.
} 
relativamente ao modelo anterior, e a arma torna-se o direito, manejado como uma tecnologia de poder pelos atores que se articulam em torno ao impedimento. Uma fraude à constituição.

$\mathrm{Na}$ segunda hipótese, mesmo que em um quadro de disputa política, funciona um mecanismo de accountability estabelecido pelos constituintes para que o parlamento, no exercício do seu dever de fiscalização em um sistema de freios e contrapesos, chame à responsabilidade o presidente que tenha cometido crimes graves, definidos de modo antecedente como passíveis de determinar o impedimento do mandato do chefe do executivo. O cumprimento da lei fundamental.

Em ambos os casos, obviamente a atuação do legislador discursivamente reporta-se ao cumprimento da constituição, já que o que diferencia uma de outra hipótese não é a justificação constitucional, mas o seu uso retórico. Também em ambos os casos, a forma seguida tende a ser a mesma, já que o que diferencia uma de outra hipótese não é o procedimento (embora eventualmente possa sê-lo), mas a questão de fundo de haver ou não realmente a hipótese legal para o impedimento e o comportamento do legislador em relação ao suposto fato.

Como em um e outro caso quem atua é o parlamento em face do executivo, sob o mesmo procedimento e com a mesma justificação constitucional, saber se se está diante de um equivalente funcional ao golpe militar ou de um mecanismo de responsabilização por crime somente pode passar por um controle externo das razões explícitas que, objetivamente, são invocadas para o impedimento, isto é, da imputação.

Tratando-se, por definição, de um discurso com pretensões de validade constitucional e legal, a sua legitimidade e juridicidade - portanto sua capacidade para produção dos efeitos jurídicos pretendidos - estão necessariamente condicionadas à verificação da presença dos pressupostos que autorizam e limitam a atuação do poder público.

No Estado Democrático de Direito essa verificação, quando não produzida em autocontrole do poder que atua, submete-se, externamente, não só ao controle social, mas sobretudo ao controle jurisdicional, em especial pelos Tribunais Constitucionais, de regra incumbidos pelas constituições nacionais de assegurar que os atos do poder público não violem direitos humanos e fundamentais. Mais recentemente, a esse controle somou-se outro, de origem internacional, por intermédio de uma atuação mais ativa de órgãos de proteção dos direitos humanos, que podem ser ativados na ausência de adequada proteção em âmbito nacional.

Tribunais Constitucionais, naturalmente, podem falhar no exercício desse controle, vislumbrando violações onde não existem, ou não as reconhecendo quando presentes. O Tribunal Constitucional é falível. Como advertiu Rui Barbosa, ele apenas erra por último. Todavia, a renúncia ao exercício do controle, um non liquet, não parece caber como opção nas modernas democracias constitucionais. 
O problema é de alta relevância. No mais recente e relevante juízo político de um chefe do poder executivo nas Américas, ocorrido no Brasil em 2016, o Tribunal Constitucional do país declarou não lhe caber incursionar, materialmente, no procedimento em curso. É dizer, o Tribunal afirmou não lhe ser possível controlar a imputação, afirmando antecipadamente que não iria fazê-lo. Para o Tribunal Constitucional brasileiro, o controle que lhe caberia seria apenas quanto à forma do procedimento, porque se trataria de um julgamento "exclusivamente político.” A afirmação, contida inicialmente no voto do Relator da ADPF 378 MC/DF, Min. Edson Fachin, consagra de maneira clara a posição absenteísta do Tribunal: “O conteúdo do juízo exclusivamente político no procedimento de impeachment é imune à intervenção do Poder Judiciário [...] que não deve adentrar no mérito da deliberação parlamentar". ${ }^{10}$

São evidentes as consequências dessa compreensão. De início, significa que o Tribunal declara não lhe competir a aferição se está diante de um manejo fraudulento, por uma maioria parlamentar, do mecanismo de responsabilização por crime de responsabilidade do chefe do poder executivo. Basta respeitar as formalidades. Em outras palavras, mesmo que presente uma das modalidades de juízo político arbitrário expostas pela investigação empírica de Pérez-Liñan na América Latina e reproduzidas na preocupação da $\mathrm{CIDH}$ encaminhada à Corte IDH, a saber, uma deposição mesmo na ausência de crime de responsabilidade, "como forma de golpe de Estado encoberto?", ${ }^{11}$ o Tribunal não reconhecerá a atuação como constitucionalmente fraudulenta. Mais: mesmo que o juízo político fira direitos humanos do chefe do poder executivo, respeitada a forma do procedimento, o Tribunal não reconhecerá a violação.

No particular, não se pode acusar o Poder Judiciário brasileiro de incoerência histórica. Em verdade, reproduz-se o padrão de comportamento da Corte Suprema brasileira e dos Tribunais Constitucionais da região em relação aos golpes civis-militares da segunda metade do século passado. Também naquele momento histórico essas Cortes não reconheceram naquelas iniciativas violações constitucionais ou aos direitos humanos dos governantes afetados. ${ }^{12}$

\subsection{POR QUE O TRIBUNAL CONSTITUCIONAL DEVE SINDICAR A IMPUTAÇÃO?}

Causa perplexidade que um Tribunal Constitucional, já institucionalizado o constitucionalismo do pós-guerra (neoconstitucionalismo), tenha declarado não lhe competir sindicar ato do Parlamento relativamente à sua compatibilidade com direitos humanos e fundamentais, exceto quanto à forma. A invocação

\footnotetext{
10 STF, 2016a, p.15-16.

11 CIDH, 2017, p.16, grifamos.

12 SCHINKE, 2015.
} 
do marco teórico neoconstitucional é relevante aqui porque tal deliberação do Tribunal Constitucional parece ressuscitar a Constituição meramente política, "pré-neoconstitucional", que se limita a estabelecer competências e separar as esferas de atribuição dos poderes públicos, sem conteúdos materiais, dotados de normatividade, que condicionam a atuação do Estado. ${ }^{13}$

A ideia de que o mérito da imputação não possa ser sindicado, gozando de imunidade material, claramente conduz a situações nada compatíveis com a volta aos valores do constitucionalismo do pós-guerra e antagoniza com o dever de garantir uma série de direitos humanos - não apenas os de devido processo - a que estão internacionalmente vinculados os Estados Partes da Convenção Americana.

Um exemplo, tão absurdo quanto possível de ocorrer na atual quadra da história parlamentar, ilustra o argumento. No direito brasileiro, configura crime de responsabilidade a conduta do chefe do poder executivo (ou de Ministro do STF) "incompatível com a dignidade, a honra e o decoro do cargo" (art.7.9 e 39.5 da Lei 1.079/50). Levando a compreensão da imunidade material do juízo político à sua consequência, o(a) Presidente da República no Brasil (ou um Ministro do STF) poderia ser afastado de suas funções pelo fato de ser, por exemplo, homossexual, desde que o parlamento brasileiro entendesse que a homossexualidade configura conduta "incompativel com a dignidade, a honra e o decoro do cargo."

O ridículo da situação hipotética visa, mesmo, chamar a atenção. Lembremo-nos do Tribunal Constitucional: o STF “não deve adentrar no mérito da deliberação parlamentar".${ }^{14}$ Veja-se que o enquadramento da opção homossexual em categorias como "dignidade", "honra" e "decoro", realizadas por expressões retóricas de moralismo conservador, constitui juízo tipicamente de "mérito" da imputação, o que, segundo a Suprema Corte, não é "passível de ser reformado, sindicado ou tisnado" pelo controle jurisdicional.

Por que o Tribunal Constitucional deve, para além das garantias de procedimento, sindicar no mérito a imputação de crime de responsabilidade, no exemplo, de homossexualidade como conduta incompatível com a dignidade, a honra e o decoro do cargo ? A resposta à indagação orienta a conclusão acerca dos limites do juizo político e do dever de controle por parte do Tribunal Constitucional: porque a imputação, não quanto a forma, mas in substantia, viola direitos humanos e fundamentais da pessoa implicada, e não pode ser enquadrada como uma hipótese típica de crime de responsabilidade.

O Tribunal Constitucional deve exercer o controle, de direito interno (constitucional) e internacional (convencional) não apenas sob o ponto de vista formal (devido processo), mas também material da violação dos direitos humanos e fundamentais da pessoa implicada no processo de impeachment. Isso não quer

13 CARBONELL, 2010.

14 STF, 2016a, p.16. 
significar que não deva fazê-lo com especial self-restraint, reconhecendo a margem de apreciação de que goza o parlamento na deliberação. Todavia, no exemplo do impeachment por homossexualidade, a deliberação parlamentar violaria - como entendeu o próprio STF relativamente ao sancionamento da homossexualidade em ambiente militar - o "direito à liberdade de orientação sexual como liberdade existencial do indivíduo", consistindo em uma "Manifestação inadmissível de intolerância que atinge grupos tradicionalmente marginalizados". ${ }^{15}$

A ideia de que não se deva controlar no mérito a acusação de impeachment, quando e se ela malfere direitos humanos e fundamentais do implicado, retira o caráter de pessoa da figura do(a) chefe do poder executivo. Trata-se de uma compreensão que desumaniza o indivíduo que ocupa o cargo para atribuir ao chamado "juízo político" imunidade material para afastar esses direitos por uma maioria parlamentar, o que configura a própria negação do sentido e da normatividade desses direitos, de natureza tipicamente contramajoritária, que dão substância a um Estado material de Direito, no âmbito do qual

[...] além da garantia de determinadas formas e procedimentos inerentes à organização do poder e das competências dos órgãos estatais, se encontram reconhecidos, simultaneamente, como metas, parâmetro e limites da atividade estatal, certos valores, direitos e liberdades fundamentais $[\ldots]^{16}$

Como se sabe, a nota de essencialidade dos direitos humanos e fundamentais qualifica esses direitos por sua oponibilidade a qualquer maioria e mesmo à unanimidade parlamentar, afastando-os de toda deliberação política que, em nome de maiorias conjunturais e circunstâncias de momento, possam avançar sobre esses direitos que representam, para não mais retroceder, marcos civilizatórios derivados do acúmulo da experiência histórica. A fundamentalidade desses direitos, que têm natureza contramajoritária por definição, reside precisamente na sua subtração "à plena disponibilidade por parte dos poderes constituídos, ainda que democraticamente legitimados para o exercício do poder." ${ }^{17}$

Portanto, não pode haver dúvida de que, mesmo reconhecida ao parlamento uma margem de apreciação na deliberação relativa à presença do crime de responsabilidade, seja porque se tratam de tipos abertos, seja porque há um marcado conteúdo político no juízo parlamentar, vinculado a critérios de conveniência e oportunidade, os limites dessa margem são determinados pelos direitos humanos e fundamentais da pessoa implicada, cujo resguardo é obrigação constitucional e convencional de todos os poderes constituídos e, precipuamente, do Tribunal Constitucional.

\footnotetext{
15 STF, 2016b.

16 SARLET, 2011, p.59.

17 SARLET, 2011, p.62.
} 


\subsection{O PARADIGMA INTERAMERICANO DE CONTROLE}

O dever de controle tem como paradigma não apenas a Constituição, mas também os tratados internacionais de direitos humanos, para o que aqui importa, especialmente um: a Convenção Americana de Direitos Humanos - CADH. Para ficar no exemplo, no caso do impeachment por homossexualidade, por mais que o procedimento formal (devido processo) fosse seguido, o mérito da imputação seria uma violação à $\mathrm{CADH}$, tendo em vista que a Corte IDH já assentou que "a orientação sexual e a identidade de gênero das pessoas são categorias protegidas pela Convenção”. De consequência, “nenhuma norma, decisão ou prática de direito interno [...] pode diminuir ou restringir, de modo algum, os direitos de uma pessoa a partir de sua orientação sexual."18

A obrigação de todos os juízes e tribunais nacionais aplicarem, inclusive de ofício, as disposições da CADH, vem afirmada pela Corte IDH desde o Caso Almonacid Arellano y otros $v$. Chile, de 2006, que instituiu o conceito de controle de convencionalidade. ${ }^{19}$ A compreensão estabelecida pelo Tribunal Interamericano é a de que suas decisões, para além de vinculantes entre as partes para o caso concreto (res judicata), cumprem uma função interpretativa erga omnes, de modo que a norma convencional interpretada (res interpretata), isto é, a jurisprudência da Corte, deve ser também observada pelos órgãos nacionais no exercício do seu dever de controle convencional. ${ }^{20}$

Portanto, há dever de controle não apenas formal (procedimental), mas da "dupla compatibilidade material" (constitucional e convencional) pela jurisdição nacional, tendo em vista que ao juízo político não se franqueia, em seu “mérito", a violação a direitos humanos e fundamentais. Não por outra razão, em âmbito interamericano a Corte IDH já declarou a responsabilidade internacional de Estados por violações de direitos humanos praticadas em decorrência de juicio político, como nos casos Tribunal Constitucional vs. Perú ${ }^{22}$ e Tribunal Constitucional (Camba Campos y Otros) vs Ecuador. ${ }^{23}$ Embora nesses casos tenham sido relevantes as alegações de violações ao devido processo legal, a Corte em nenhum momento restringe ao aspecto procedimental o controle convencional do juízo político, afirmando, pelo contrário, que toda a atividade estatal encontra limites nos direitos consagrados na Convenção. A Corte é expressa em consignar, em ambos os casos, que

\footnotetext{
18 CORTE IDH, 2016, $\$ 104$.

19 MAZZUOLI, 2011.

20 CORTE IDH, 2013.

21 MAZZUOLI, 2011.

22 CORTE IDH, 2001a.

23 CORTE IDH, 2013.
} 
O respeito aos direitos humanos constitui um limite à atividade estatal, o qual vale para todo órgão ou funcionário que se encontre em uma situação de poder, em razão de seu caráter oficial, relativamente às demais pessoas. É, assim, ilícita, toda forma de exercício do poder público que viole os direitos reconhecidos pela Convenção. ${ }^{24}$

A compreensão da CIDH não parece divergir. No caso Tribunal Constitucional vs Ecuador, por exemplo, a CIDH apontou violação - ocorrida em juízo político realizado pelo parlamento equatoriano para afastar magistrados do Tribunal Constitucional - ao direito às garantias judiciais, ao princípio da legalidade e à proteção judicial (arts. 8, 9 e 25 da CADH), combinados com os arts. 1.1 (obrigação de respeitar os direitos) e 2 (dever de adotar disposições de direito interno) da Convenção. A causa invocada pelo Parlamento para, mediante julgamento político, depor os magistrados do Tribunal Constitucional, era uma suposta ilegalidade na forma de votação de suas nomeações. O Parlamento, evidentemente, ao depor os magistrados, reportou-se ao direito constitucional equatoriano, afirmando estar agindo em nome das leis e da Constituição do país, no seu dever legal e institucional. ${ }^{25} \mathrm{Na}$ base da iniciativa parlamentar, entretanto, de modo inconfesso estavam decisões da Corte Constitucional que contrariavam a vontade da maioria legislativa, declarando inconstitucionais duas leis. Com este contexto, a CIDH sustentou que o impeachment dos magistrados se deu por motivações exclusivamente políticas, distantes do cumprimento da obrigação parlamentar de controle das faltas graves cometidas por estes agentes políticos. A suposta ilegalidade da nomeação dos magistrados, invocada para a deposição, seria apenas uma justificação retórica para impor uma sanção de fato, descumprindo o princípio da legalidade. ${ }^{26}$

No que aqui importa, antes de submeter o caso à Corte, a CIDH havia recomendado ao Estado do Equador que, relativamente ao juízo político de agentes políticos, tomasse as medidas necessárias para que a normativa interna e a prática relevante obedecessem a critérios claros, observada a Convenção Americana. Submetido o caso ao Tribunal Interamericano, o Equador reconheceu sua responsabilidade internacional no episódio, admitindo haver violado o direito às garantias judiciais (art.8) e à proteção judicial (art.25), bem como o princípio da legalidade, estabelecido no art.9 da Convenção. No que diz respeito à legalidade, reconheceu que não se observou uma causa determinada em lei, considerando a falta de certeza legal relativamente aos motivos para um afastamento dos magistrados de seus cargos. ${ }^{27}$ Já a Corte IDH, ao avaliar a causa invocada pelo Congresso para a destituição, isto é, a imputação feita aos magistrados,

24 CORTE IDH, 2001a, \$68; CORTE IDH, 2013, \$166.

25 CORTE IDH, 2013.

26 CORTE IDH, 2013.

27 CORTE IDH, 2013. 
entendeu que se o Parlamento considerava o modo de votação irregular, não havia explicação para que esperasse mais de um ano e meio para adotar uma medida contra a irregularidade, o tendo feito somente no contexto de uma crise política entre os poderes do Estado. Dentre outros elementos contextuais que precederam o julgamento político e foram observados pela Corte, apontou-se que, relativamente à irregularidade imputada, não havia qualquer anterior ação legislativa, administrativa ou judicial que questionasse o mecanismo de nomeação que foi utilizado como causa para determinar o impedimento. Nesse contexto, a Corte considerou que as deliberações do Congresso, a despeito de sua retórica de justificação constitucional,

[...] não foram adotadas em virtude da exclusiva valoração de uns dados fáticos concretos e com o fim de dar o devido cumprimento a legislação vigente, senão que perseguiam um fim completamente distinto e relacionado com um desvio de poder dirigido a obter o controle da função judicial através de diferentes procedimentos, neste caso, a cassação e os julgamentos políticos. ${ }^{28}$

O Tribunal Interamericano entendeu, assim, restarem violados os arts.8.1, 8.2 e 8.4, em combinação com o art.1.1 da CADH, em virtude da deposição arbitrária realizada por intermédio destes julgamentos políticos, que vulneravam as garantias judiciais, inclusive a de imparcialidade do julgador, dos magistrados depostos. Entendeu ainda que a prática do Estado equatoriano violou o direito político dos magistrados de ter acesso e permanência, em condições de igualda$d e$, às funções públicas de seu país, nos termos do art.23, “c”, da CADH. Tendo encontrado desde logo estas violações, a Corte entendeu desnecessário avançar sobre a existência ou não de violação a outros direitos previstos na Convenção, como o princípio da legalidade. ${ }^{29}$

Posteriormente, quando a CIDH submeteu à Corte IDH uma solicitação de Opinião Consultiva sobre o standard interamericano de controle em juízos políticos de chefes de poder executivo, não apenas o fez no que diz respeito às garantias do devido processo (arts. 8 e 25, da CADH), mas também em relação ao princípio da legalidade (art.9) e a garantia de direitos políticos (art.23) do cidadão implicado no processo de deposição parlamentar. A CIDH correlacionou os direitos invocados com tratado regional que assegura a democracia nas Américas, a Carta Democrática Interamericana, expressando sua preocupação em salvaguardar tanto direitos humanos como a institucionalidade democrática, protegendo tanto a pessoa submetida a juízo político como a sociedade em geral. ${ }^{30}$

Nesse contexto, embora o devido processo, com todas as garantias, seja um elemento indispensável da validade dos juízos políticos, não parece ser possível falar em controle meramente procedimental dos julgamentos com essa natureza,

28 CORTE IDH, 2013, $\$ 219$.

29 CORTE IDH, 2013.

30 CIDH, 2017. 
franqueando-se-lhes a violação de direitos humanos e fundamentais em uma perspectiva material. Como apontam (i) a pesquisa empírica sobre as experiências da região, (ii) o exemplo hipotético do impeachment por homossexualidade, (iii) a jurisprudência da Corte IDH sobre juicios políticos ou (iv) as manifestações da CIDH sobre os recentes casos de impeachment nas Américas, a própria imputação deve ser submetida a escrutínio, sendo tisnada pela jurisdição nacional ou internacional quando se afastar dos parâmetros de validade formal e material estabelecidos na Constituição e na Convenção Americana de Direitos Humanos.

\section{CONTEÚDO DO PRINCÍPIO DA LEGALIDADE, COMO DI- REITO HUMANO, NO CONTROLE DO JUÍZO POLÍTICO}

Dentre os direitos humanos e fundamentais cuja violação deve ser controlada pelo parlamento e pela jurisdição, nacional e internacional, está o princípio da legalidade. O princípio, um clássico dentre os direitos do homem desde a Revolução Francesa, vem reconhecido nos mais importantes tratados de direitos humanos: art.11 da Declaração Universal de Direitos Humanos (1948); art.7 da Convenção Europeia de Direitos Humanos (1950); art.15 do Pacto Internacional de Direitos Civis e Políticos (1966); art.9 da Convenção Americana de Direitos Humanos (1969); art.7 da Carta Africana de Direitos Humanos (1981); art.49 da Carta de Direitos Fundamentais da União Europeia (2000); art.15 da Carta Árabe de Direitos Humanos (2004). ${ }^{31}$

No que diz respeito ao seu conteúdo normativo, é relativamente uniforme no âmbito do direito internacional dos direitos humanos o entendimento de que o princípio da legalidade se aplica ao direito sancionatório como um todo, não se restringido ao direito penal propriamente dito. $\mathrm{Na}$ Corte IDH, no Caso Baena Ricardo y otros a Corte assentou que as sanções administrativas são como as penais, uma expressão do poder punitivo do Estado, razão pela qual tem natureza similar a estas, sofrendo incidência do princípio da legalidade. ${ }^{32}$ Já no caso de julgamento político, como no Caso Tribunal Constitucional vs Ecuador, em que o Estado reconheceu, após denúncia da $\mathrm{CIDH}$, ter violado o princípio da legalidade, a Corte não cogitou de que se não aplicasse o princípio aos processos de impedimento. ${ }^{33}$ Não por outra razão, em seu pedido de opinião consultiva a $\mathrm{CIDH}$ afirma que a jurisprudência da Corte é segura em reconhecer a incidência do princípio da legalidade não apenas em âmbito penal, mas “a todo proceso que pueda entenderse sancionatorio" impondo uma "cuidadosa verificación de la efectiva existencia de la conducta ilícita." ${ }^{34}$

\footnotetext{
31 TULKENS, 2011.

32 MEDINA QUIROGA, 2005; CORTE IDH, $2001 \mathrm{~b}$.

33 CORTE IDH, 2013.

34 CIDH, 2017, p.7.
} 
Não parece haver dúvidas, em tal cenário, senão por força do que estabelece nossa Constituição, pelo que determina a $\mathrm{CADH}$, de que o princípio da legalidade deva incidir no Brasil para o constitucionalmente denominado crime de responsabilidade (art.85, CF), ${ }^{35}$ também infração político-administrativa, cuja

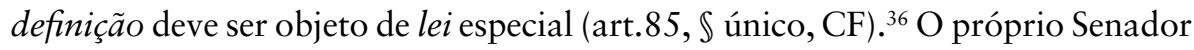
Anastasia, autor do Parecer cuja aprovação instaurou o processo de impeachment, após afastar o argumento defensivo de que se haviam de aplicar as garantias de direito penal e processual penal às infrações político-administrativas, registrou que isso não implicaria “afastar princípios caros ao Estado Democrático de Direito, especificamente no âmbito do Direito Sancionador." ${ }^{37}$ Entender, portanto, na esteira da compreensão própria do direito internacional dos direitos humanos, que devendo ser aplicado o princípio da legalidade ao direito sancionatório como um todo, não devesse estar presente no crime de responsabilidade, configuraria um evidente drible retórico para afastar dessa categoria de infração um poderoso instrumento de controle do exercício arbitrário do poder estatal de acusar e julgar, expondo a violações não apenas a figura humana implicada no julgamento, mas a institucionalidade democrática de modo geral.

Aqui, por mais que o STF tenha - no voto do Relator da ADPF $378 \mathrm{MC} /$ DF, no ponto sem dissenso aparente - se manifestado no sentido de que a atuação da jurisdição deveria restringir-se ao controle da "forma do procedimento", incluiu nesta dimensão o princípio da legalidade, assim:

Restringe-se a atuação judicial, na hipótese, à garantia do devido processo legal. A forma do procedimento de impeachment deve observância aos direitos e garantias do acusado, especialmente aos princípios da legalidade, do devido processo legal, do contraditório e da ampla defesa, previstos pela Constituição da República e pela Convenção Americana de Direitos Humanos (Pacto de São José da Costa Rica). ${ }^{38}$

Não está claro, em virtude da declarada restrição do controle ao procedimento, se a legalidade a que se refere o julgado é a legalidade processual - procedimento estabelecido em lei - ou o princípio da legalidade no sentido da lex praevia, scripta, stricta et certa, neste escrito privilegiado, que não é de conteúdo processual. Nessa dimensão, a legalidade não assegura a forma do procedimento, mas submete a própria imputação a controle. Saber se a conduta imputada corresponde a uma conduta previamente estabelecida no direito interno com suficiente clareza não é um juízo da forma do procedimento, mas um juízo de adequação típica, vinculado, na perspectiva do direito internacional dos direitos

\footnotetext{
35 BRASIL, 1988.

36 BRASIL, 1988.

37 SENADO FEDERAL, 2016a, pp.17-18, grifamos.

38 STF, 2016a, p.16.
} 
humanos, ao princípio da legalidade, capaz de sindicar o cerne da imputação, o que expressamente afirmou não poder fazer o Tribunal Constitucional brasileiro.

De fato, na perspectiva do direito internacional dos direitos humanos, o princípio da legalidade não é compreendido desde uma análise simplória da acusação, que limitaria a normatividade do princípio à exigência de uma lei formal antecedente, bastando para sua observância que a atividade estatal sancionadora reporte-se, em justificação retórica de sua atuação, a uma lei. Fosse assim, toda a acusação e sanção estatais obedeceriam à legalidade, já que dificilmente os órgãos estatais envolvidos não justificariam sua atuação em uma precedente disposição legal. Por isso é que, a despeito de a remissão à lei que prevê a infração e sua sanção ser necessária para a validade da atuação estatal, o conteúdo normativo do princípio da legalidade, no que se direciona ao julgador, não se circunscreve a isso, alcançando, pelo contrário, todo o comportamento estatal anterior relativamente a infração indicada, é dizer, o estado do direito ao tempo dos fatos, fins de preservar a ratio essendi da legalidade e dos princípios que lhe são subjacentes.

A perspectiva do direito internacional é relevante - sobretudo para contrastar com um ambiente doméstico de disputa retórica -, porque aborda o direito interno e o conjunto de práticas estatais de maneira "descritiva". De fato, no controle internacional de convencionalidade, as leis e demais atos normativos nacionais ou as decisões dos tribunais domésticos são "simples fatos" perante as instâncias internacionais. ${ }^{39}$ São justamente as práticas nacionais legislativas, executivas ou judiciais, vistas "como um todo", que estarão submetidos à instância internacional de controle, como fatos que revelam o comportamento do sujeito de direito internacional que é o Estado.

Tal perspectiva favorece ideais como igualdade e segurança jurídica, estruturais ao Estado de Direito e umbilicalmente conectados ao princípio da legalidade. Com efeito, a Corte IDH aponta como fundamento central do princípio da legalidade a exigência de segurança jurídica. ${ }^{40}$ Impõe-se que a norma punitiva, seja penal ou administrativa, exista e resulte conhecida antes do fato que se pretende sancionar, sem o que os indivíduos não teriam como orientar seu comportamento de acordo com uma ordem jurídica vigente e conhecida, na qual se expressam a reprovabilidade social de determinada conduta e suas consequências.

A dimensão enfatizada pela Corte representa, ademais, uma projeção da ideia de igualdade no princípio da legalidade, no sentido em que se promove justiça com regularidade ${ }^{41}$ ao exigir uma lei antecedente ao fato e clareza normativa suficiente (determinação) para que a norma possa servir de orientação de condutas, garantindo que os indivíduos somente serão submetidos a intervenções estatais sancionadoras quando e se praticarem condutas previamente definidas como

\footnotetext{
39 RAMOS, 2009.

40 CORTE IDH, 2010.

41 RAWLS, 1997.
} 
sancionáveis. Tais diretrizes pretendem evitar uma especifica forma de injustiça que se consolida na aplicação casuística e aleatória de juízos sancionatórios. Com tal conteúdo, o princípio da legalidade constrange a atividade do aplicador com o objetivo de que aqueles submetidos a juízos sancionatórios recebam o mesmo tratamento diante das mesmas condutas.

Assim compreendido, a potência do princípio da legalidade - originalmente não concebido para assegurar a institucionalidade democrática - está em que agora também pode atuar para que indivíduos no exercício do cargo de chefe de poder executivo não sejam depostos por aplicação casuística e aleatória do direito interno, em burla retórica à constituição e às leis, em contextos de disputa política, crise macroeconômica e desaprovação popular. Em sua normatividade como direito humano, o princípio atua para que agentes políticos somente sejam submetidos a impedimento quando e se praticarem condutas previamente definidas como passíveis de interrupção do mandato, a partir de uma avaliação da prática e do direito estatal como um todo, e de sua coerência com a imputação.

\section{DIREITO HUMANO À LEGALIDADE E O CASO BRASILEIRO}

Como tivemos a oportunidade de explicitar acima, no Caso do Tribunal Constitucional vs Ecuador, ${ }^{42}$ o Equador reconheceu a violação ao princípio da legalidade (art. $\left.9^{\circ}, \mathrm{CADH}\right)$, tendo em vista a inobservância de uma causa objetivamente prevista em lei para afastamento dos magistrados de seus cargos, considerando a falta de certeza legal relativamente aos motivos determinantes. No que aqui importa, é relevante perceber que, para considerar arbitrário o impedimento dos magistrados, sem base jurídica antecedentemente determinada, a Corte IDH e a Comissão avaliaram a prática e o direito estatal como um todo, além do contexto político que precedeu ao afastamento dos magistrados, ingressando na imputação e nas motivações presentes nas transcrições do julgamento parlamentar.

Dentre outras considerações, a Corte incorporou o argumento da CIDH de que, antes do afastamento, e já transcorrido um ano e meio da nomeação dita irregular, não havia qualquer ação legislativa, administrativa ou judicial que questionasse o mecanismo de nomeação que, repentinamente, foi utilizado como causa para determinar o impedimento. É dizer, a prática estatal anterior não era coerente com o entendimento repentino, surgido em meio a uma crise entre os poderes, de que havia no fato invocado uma infração grave determinante do afastamento daqueles agentes políticos. ${ }^{43}$

A Corte IDH, conforme já se apontou, à guisa de qualificar jurídico-convencionalmente a arbitrariedade, a ausência de previsão normativa suficien-

\footnotetext{
42 CORTE IDH, 2013.

43 CORTE IDH, 2013.
} 
temente determinada para o afastamento dos agentes políticos e aquela atuação ad hoc do parlamento, entendeu violadas garantias de procedimento, deixando de pronunciar-se sobre o princípio da legalidade, cuja violação fora denunciada pela Comissão e reconhecida pelo Estado. A situação todavia, era (também) de violação à legalidade (art.9), tendo a Corte perdido a oportunidade de reafirmar a normatividade do princípio em sua perspectiva convencional.

É importante perceber que a sentença - para além do que apontou a $\mathrm{CIDH}$ e o próprio Estado reconheceu em relação ao art.9 - enfatiza uma série de aspectos relacionados ao princípio da legalidade, como a arbitrariedade na aplicação da norma, a insegurança jurídica, a inexistência de motivos suficientemente claros para o julgamento político e uma atuação estatal ad hoc, inusitada em face do comportamento estatal anterior relevante. Portanto, como salientou em voto dissidente o juiz interamericano Ferrer Mac-Gregor, era necessário que a Corte, sob estes mesmos pressupostos fáticos, avaliasse e declarasse a violação ao princípio da legalidade, especialmente para afirmar, sob a égide desse princípio, a necessidade de clareza e determinação suficientes nos supostos fáticos que dão causa ao impedimento, fins de promover a segurança jurídica e prevenir juízos políticos arbitrários que, a pretexto de cumprir a Constituição, constituam verdadeiramente desvios de poder. ${ }^{44}$

A pertinência de tais considerações para o processo de impeachment de Dilma Roussef são autoevidentes.

$\mathrm{Na}$ ADPF 378 pretendeu-se que o Supremo Tribunal Federal enunciasse, antes de efetivamente instaurado o processo de impeachment da então Presidente de República, quais as "regras do jogo", para os fins, expressamente declarados, de mitigar a judicialização do processo e atribuir-lhe segurança jurídica. ${ }^{45} \mathrm{O}$ Supremo fez mais que isso: declarou, antecipadamente, os limites de sua possível atuação em face do processo. Para além de interpretar a compatibilidade de dispositivos da Lei 1.079/50 com a Constituição, o Tribunal declarou, de ofício, que não se imiscuiria no mérito da imputação e da deliberação parlamentar, afastando, “cautelarmente", qualquer possível provocação a propósito. E fez constar na Ementa do Acórdão:

O conteúdo do juízo exclusivamente político no procedimento de impeachment é imune à intervenção do Poder Judiciário, não sendo passível de ser reformado, sindicado ou tisnado pelo Supremo Tribunal Federal, que não deve adentrar no mérito da deliberação parlamentar. ${ }^{46}$

A denúncia por supostos crimes de responsabilidade praticados pela então Presidente da República foi recebida pelas imputações de (i) abertura de créditos

\footnotetext{
44 CORTE IDH, 2013.

45 STF, 2016c.

46 STF, 2016a, pp.15-16.
} 
suplementares sem autorização do Congresso Nacional, e (ii) contratação ilegal de operações de crédito com instituição financeira controlada pela União. ${ }^{47}$ Conforme registrou o então Presidente da Câmara dos Deputados, Eduardo Cunha, ao admitir a representação por crime de responsabilidade, a peça indicava decretos assinados pela Presidente da República, no exercício financeiro de 2015, em desacordo com a Lei de Diretrizes Orçamentárias. Tal prática configuraria, segundo a representação, as hipóteses do art. 10, itens 4 e 6 da Lei 1.079/50, na medida em que infringia dispositivo da lei orçamentária (item 4) e promovia a abertura de créditos sem observância das prescrições legais (item 6). Adicionalmente, a representação apontava, novamente por infração à lei orçamentária, a prática das chamadas "pedaladas fiscais". A denunciada teria promovido a contratação de operações de crédito ilegais com o Banco do Brasil e com a Caixa Econômica Federal, bancos públicos que teriam realizado adiantamentos ao Poder Executivo, de modo a atuar não apenas como agentes intermediadores de programas governamentais, como estariam autorizados, mas como agentes financiadores do governo, tudo sem o devido registro na contabilidade oficial da União. ${ }^{48}$

Relativamente à primeira imputação (i), a defesa da denunciada alegou perante o Parlamento que "A sistemática de abertura de créditos suplementares por decreto é a mesma desde 2001." ${ }^{49}$ e que "O Poder executivo sempre se pautou pelos entendimentos da corte de contas e por toda a jurisprudência referente à publicação dos decretos de crédito suplementar.". ${ }^{50}$

No que diz respeito à segunda imputação (ii), a alegação de alteração $a d$ hoc de posicionamento anterior dos órgãos de controle se reproduz. A defesa da imputada alegou haver "uma guinada brusca de rota jurisprudencial, posto que desde a entrada em vigor da Lei de Responsabilidade Fiscal essa tese nunca havia sido suscitada, nem pelo órgão de controle e nem pela doutrina especializada." ${ }^{51}$

Não há no presente escrito qualquer pretensão de julgar a procedência de tais asserções, para o que seria necessário imiscuir-se nas deliberações da Corte de Contas brasileira durante razoável período histórico, para além de outras fontes normativas e práticas estatais relevantes. Todavia, parece inequívoco que, tendo em conta o quanto expusemos relativamente ao princípio da legalidade, a alegação defensiva mereceria enfrentamento jurisdicional, reconhecendo-se uma violação à legalidade constitucional e convencional na hipótese de que se confirmassem tais alterações abruptas da orientação dos órgãos de controle, em momento de crise macroeconômica e de conflito entre poderes, justamente para promover a deposição presidencial.

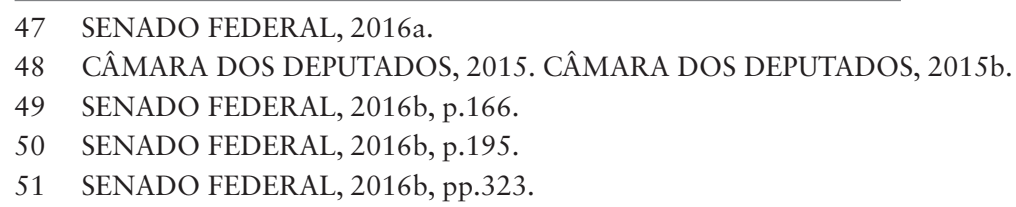


Para tal enfrentamento, o STF deveria submeter à escrutínio a própria imputação, tendo em vista que ao juízo político não se franqueia, em seu "mérito", a violação a direitos humanos e fundamentais. Ao declarar a imunidade da deliberação parlamentar, no mérito, ao controle jurisdicional, o órgão de cúpula do Poder Judiciário brasileiro, além de encampar uma potencial infringência ao art. 9 (princípio da legalidade) da CADH, promove uma violação ao art. 25 (direito à proteção judicial) da Convenção pelo Brasil, sujeitando a República à responsabilidade internacional.

\section{CONCLUSÕES}

$\mathrm{Na}$ ciência política, a literatura especializada documenta a existência de procedimentos de impeachment realizados com desvio de poder. Processos e julgamentos cuja iniciativa e resultado não estiveram atrelados ao cumprimento da Constituição, mas sim constituíram um equivalente funcional dos golpes civis-militares que marcaram o continente latino-americano durante a Guerra Fria, utilizando-se o direito como arma de disputa política no jogo das relações de poder. Por outro lado, casos há em que, sem prejuízo do componente político inerente ao processo, tratou-se de chamar à responsabilidade chefes do poder executivo responsáveis pelo cometimento de infrações antecedentemente definidas como impeditivas da continuidade do mandato.

No direito, as manifestações dos órgãos do sistema interamericano de direitos humanos quando da oportunidade de apreciação de juicios politicos escrutinaram as razões aparentes e as ocultas para o fim de avaliar o procedimento e as imputações feitas contra agentes políticos para determinar o afastamento de suas funções. Nessas avaliações, observaram o direito e a prática estatal relevante não só no momento dos fatos, mas também no período que precedeu ao julgamento político, fins de alcançar compreensão sobre eventual arbitrariedade da atuação estatal em face do indivíduo implicado, que não tem suspendidos, por sua posição na estrutura estatal, seus direitos humanos e fundamentais. Não se cogitou, nessas oportunidades, que no controle sobre a violação de direitos humanos o escrutínio jurisdicional sobre o julgamento político devesse se limitar ao procedimento, franqueando-se às maiorias parlamentares, no exercício dessa sua função anômala de julgamento, a violação de direitos humanos do implicado, em uma dimensão material.

A efeitos de permitir o controle da instrumentalização do direito no jogo das disputas políticas, o princípio da legalidade é um direito humano cujo controle da não violação é essencial em episódios de impeachment, tendo em vista que tais episódios, como documentou a literatura especializada, em geral estão emoldurados por pressões midiáticas e de organizações sociais favoráveis ao afastamento presidencial, forçando e condicionando a atuação do legislador em contextos de crise macroeconômica e disputa entre poderes. Contudo, o indivíduo 
sentado à cadeira presidencial não se despe de seus atributos enquanto pessoa. Violações à sua dignidade e direitos humanos não estão autorizadas em virtude do pensamento, ainda que generalizado, de que não sirva mais ao cargo.

Como tivemos a oportunidade de expor, o princípio da legalidade tem justamente a finalidade de afastar julgamentos arbitrários, traduzindo ideais de clareza, anterioridade, acessibilidade e previsibilidade das proibições e das atuações estatais correspondentes, de modo a permitir aos indivíduos a conformação de sua conduta ao tempo em que realizadas, mediante o conhecimento dos limites de sua esfera negativa de liberdade. O princípio é uma concreção de diversos aspectos que conformam a ideia fundamental de um Estado Democrático de Direito.

Não por outra razão, no direito internacional dos direitos humanos o controle da observância do princípio da legalidade não se restringe à análise da justificação formal do Estado para sua intervenção sancionadora, em sede administrativa ou penal. Para garantir o effet utile do princípio da legalidade, assegurando o objeto e o fim de sua previsão enquanto direito humano em nível internacional, é necessário explorar todo o direito e a prática estatal relevantes, o que compreende o comportamento estatal e os atos normativos existentes antes do fato havido por infracional, capazes de fornecer elementos de convicção sobre a criação, ex post facto e direcionada a determinado caso, de uma hipótese de sancionamento anteriormente não suficientemente determinada.

Para o caso brasileiro, alegadamente (i) as chamadas "pedaladas fiscais" teriam sido praticadas por todos os governos federais anteriores, ${ }^{52}$ e ainda, pela maioria dos governadores estaduais, ${ }^{53}$ sem iniciativa ou notícia de sancionamento pelos órgãos de controle. Ademais, supostamente (ii) as ditas aberturas de crédito suplementar teriam sido praticadas, para além dos governos anteriores, também pelo Vice-Presidente da República, ${ }^{54}$ que ascendeu ao poder com a deposição da titular, também sem iniciativa ou notícia de sancionamento pelos órgãos de controle. Tais fatos - lidos em conjunto com a defesa apresentada pela imputada perante o Parlamento -, acaso procedentes, representariam uma mudança arbitrária da prática estatal relevante e da compreensão do direito ao tempo dos fatos, sugerindo uma instrumentalização do direito para promover o afastamento de um chefe de poder executivo pelo parlamento em momento de crise macroeconômica, disputa entre poderes e desaprovação popular do implicado. Portanto, constituiriam uma violação ao art. 9 da Convenção Americana de Direitos Humanos, cujo dever de controle em âmbito doméstico incumbia, no caso concreto, ao Supremo Tribunal Federal, obrigado à proteção judicial de que trata o art.25 da CADH.

\footnotetext{
52 TERRA, 2016.

53 CAMAROTTO e MARCHESINI, 2016.

54 G1, 2015.
} 


\section{REFERÊNCIAS}

BRASIL. Constituição da República Federativa do Brasil de 1988. Disponível na internet em http://www.planalto.gov.br/ccivil_03/Constituicao/Constituicao. htm. Acesso em 30/06/2018.

CÂMARA DOS DEPUTADOS. Decisão da Presidência. Eduardo Cunha. 2015. Disponível em http://www.camara.gov.br/internet/agencia/pdf/Decis\%C3\%A3o_ sobre_impeachment_CD.pdf. Acesso em 01/07/2018.

CÂMARA DOS DEPUTADOS. Denúncia por crime de responsabilidade - DCR 01/2015. Hélio Pereira Bicudo, Miguel Reale Junior, Janaina Conceição Paschoal. 2015b. Disponível em http://www.camara.gov.br/proposicoesWeb/fichadetramit acao?idProposicao=2057823. Acesso em 10/06/2018.

CAMAROTTO, Murillo; MARCHESINI, Lucas. Se Impeachment for por pedaladas, 16 governadores terão que se afastar. Valor Econômico, 22 mar. 2016. Disponível em http://www.valor.com.br/politica/4493408/se-impeachment-porpedaladas-16-governadores-terao-que-se-afastar. Acesso em 10/07/2018.

CARBONELL, Miguel. El Neoconstitucionalismo: significado y niveles de análisis. In: Org. CARBONELL, Miguel; JARAMILLO, Leonardo García. El canon neoconstitucional. Madrid: Ed. Trotta, 2010, pp.153-164.

CIDH. Solicitud de Opinión Consultiva a La Corte Interamericana de Derechos Humanos. Democracia y Derechos Humanos en Contextos de Juícios Políticos. Washington, Octubre 2017.

CORTE IDH. Caso Baena Ricardo y otros Vs. Panamá. Fondo, Reparaciones y Costas. Sentencia de 2 de febrero de 2001b. Serie C No. 72.

CORTE IDH. Caso del Tribunal Constitucional (Camba Campos y otros) Vs. Ecuador. Excepciones Preliminares, Fondo, Reparaciones y Costas. Sentencia de 28 de agosto de 2013b. Serie C No. 268.

CORTE IDH. Caso del Tribunal Constitucional Vs. Perú. Fondo, Reparaciones y Costas. Sentencia de 31 de enero de 2001a. Serie C No. 71.

CORTE IDH. Caso Duque Vs. Colombia. Excepciones Preliminares, Fondo, Reparaciones y Costas. Sentencia de 26 de febrero de 2016. Serie C No. 310.

CORTE IDH. Caso Gelman Vs. Uruguay. Supervisión de Cumplimiento de Sentencia. Resolución de 20 de marzo de 2013a.

CORTE IDH. Caso Vélez Loor Vs. Panamá. Excepciones Preliminares, Fondo, Reparaciones y Costas. Sentencia de 23 de noviembre de 2010 Serie C No. 218.

CORTE IDH. Resolución de La Corte Interamericana de Derechos Humanos de 
29 de mayo de 2018. Solicitud de Opinión Consultiva presentada por la Comisión Interamericana de Derechos Humanos.

G1. Temer assinou abertura de créditos suplementares, G1, 8 dez. 2015. Disponível em http://g1.globo.com/politica/noticia/2015/12/temer-assinouabertura-de-creditos-suplementares.html. Acesso em 10/07/2018.

MAZZUOLI, Valério de Oliveira. O controle jurisdicional da convencionalidade das leis. 2 ed. São Paulo: RT, 2011.

MEDINA QUIROGA, Cecilia. La Convención Americana: Teoría y Jurisprudencia. Vida, Integridad Personal, Libertad Personal, Debido Proceso y Recurso Judicial. Santiago: Facultad de Derecho, Universidad de Chile, Centro de Derechos Humanos, 2005.

MENEZES, Wagner. Derecho internacional en América Latina. Trad. Ana Carolina Izaga de Senna Ganem. Brasília: Fundação Alexandre Gusmão, 2010.

RAMOS, André de Carvalho. Supremo Tribunal Federal brasileiro e o controle de convencionalidade: levando a sério os tratados de direitos humanos. Revista da Faculdade de Direito da Universidade de São Paulo, v. 104, p. 241 - 286, jan./ dez. 2009.

RAWLS, John. Uma teoria da justiça. Trad. Almiro Pisetta e Lenira Esteves. São Paulo: Martins Fontes, 1997.

SARLET, Ingo Wolfgang. A eficácia dos direitos fundamentais: uma teoria geral dos direitos fundamentais na perspectiva constitucional.10 ed. rev.atual. e ampl., Porto Alegre: Livraria do Advogado, 2010.

SCHINKE, Vanessa. Judiciário e Autoritarismo: estudo comparado entre Argentina e Brasil. Rev. Fac. Direito UFMG, Belo Horizonte, n. 67, pp. 677 703, jul./dez. 2015.

SENADO FEDERAL. Alegações Finais. Adv. José Eduardo Cardoso, 2016b. Disponível em http://www12.senado.leg.br/noticias/arquivos/2016/07/28/ alegacoes-finais-da-denunciada. Acesso em 28/07/2016.

SENADO FEDERAL. Parecer s/n. de 2016. Relator Sen. Antonio Anastasia. 2016a. Disponível em http://www12.senado.leg.br/noticias/arquivos/2016/05/04/ veja-aqui-a-integra-do-parecer-do-senador-antonio-anastasia. Acesso em 10/07/2018.

STF. ADPF 291. Relator(a): Min. Roberto Barroso, Tribunal Pleno, julgado em 28/10/2015, publicado em 11-05-2016b.

STF. ADPF 378 MC. Relator(a): Min. Edson Fachin, Relator(a) p/ Acórdão: Min. Roberto Barroso, Tribunal Pleno, julgado em 17/12/2015, publicado em 08-032016a, Inteiro Teor. 
STF. ADPF 378 MC. Relator(a): Min. Edson Fachin, Relator(a) p/ Acórdão: Min. Roberto Barroso, Tribunal Pleno, julgado em 17/12/2015, publicado em 08-032016c, Petição Inicial.

STJ, REsp 154.857/DF. Rel. Ministro Luiz Vicente Cernicchiaro, Sexta Turma, julgado em 26/05/1998, DJ 26/10/1998, p. 169, Inteiro Teor.

TERRA. Todos os governos anteriores praticaram pedaladas, diz Dilma. Terra, 31 mar. 2016. Disponível em https://noticias.terra.com.br/brasil/politica/ impeachment/dilma-governos-anteriores-deveriam-ter-sofrido-impeachmentpor-pedaladas,01ca4b3acd05e9dae009d1353d232b28owgc1wfp.html. Acesso em 10/07/2018.

TULKENS, Françoise. The Paradoxical Relationship between Criminal Law and Human Rights. J Int Criminal Justice. v. 9, I. 3, July 2011, Oxford University Press, pp. $577-595$.

ZAFFARONI, Eugenio Raul. Criminología: aproximación desde un margen. V.1. Themis: Bogotá, 1988.

Recebido em: 30/07/2018.

Aprovado em: 07/05/2019. 


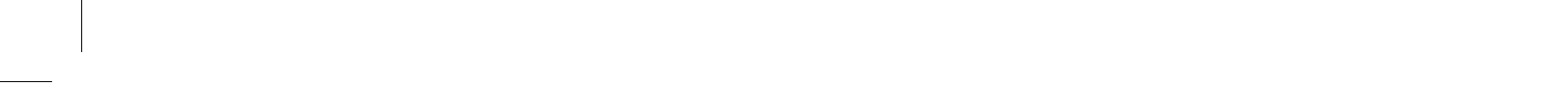

